\title{
FEM-DEM Modeling for Out-of-plane Loaded Masonry Panels: A Limit Analysis Approach
}

\author{
Emanuele Reccia*, ${ }^{*}$, Antonio Cazzani ${ }^{2}$ and Antonella Cecchi ${ }^{1}$ \\ ${ }^{1}$ Università IUAV di Venezia, Dorsoduro 2206, 30122, Venezia, Italy \\ ${ }^{2}$ Università degli Studi di Cagliari, via Marengo 2, 09123 Cagliari, Italy
}

\begin{abstract}
In this work the performances of the Discrete Element Method (DEM) applied to kinematic limit analyses of the out-of-plane behavior of masonry wall panels (with different textures) are investigated.

A discrete model of masonry is proposed, which assumes that rigid blocks are connected by a mortar interface: this is appropriate for historical masonry, where mortar is much more deformable than blocks and joints thickness is negligible. Therefore blocks can be modeled as rigid bodies connected by zero thickness Mohr-Coulomb-type interfaces.

The applied method is known as FEM/DEM, which combines finite and discrete element models.

A comparison with well-known and meaningful examples presented by Giuffrè has been carried out in order to validate this method for studying the behavior of masonry. For this purpose, 2D DEM models reproducing walls sections have been considered: they reproduce masonry walls with different staggered blocks, in particular stack bond and running bond patterns, subjected to lateral loads.
\end{abstract}

Keywords: Discrete elements, masonry, out-of-plane behavior.

\section{INTRODUCTION}

Masonry is a heterogeneous material obtained by the regular repetition of blocks and mortar, which is laid between them. A wide set of models exists in the literature, which are apt to investigate masonry behavior. Heterogeneity and nonlinear behavior make modeling masonry a difficult task.

If attention is focused on the characteristic length of analysis, two scales may be pointed out: the micro-scale and the macro-scale. As it is well known, the field-problem formulation is strongly influenced by the characteristic length.

At the micro-scale level the characteristic length is represented by blocks. Attention is devoted to interactions between blocks through mortar joints that may be modeled as an interface or as a continuum material characterized by either a linear or a nonlinear response. Hence, the need of keeping at a reasonable size the complexity of the computational problem, allows only limited portions of a masonry structure - i.e. piers, spanned beam, lintels, etc. to be studied [1-7].

At the macro-scale level the characteristic length is represented by macro-elements like masonry panels. They could be modeled as simple equivalent systems, so that they

*Address correspondence to this author at the Università IUAV di Venezia, Dorsoduro 220630122 Venezia, Italy; Tel: +39 041257 1297;

Fax:+39041522 3627; E-mails: emreccia@iuav.it,

emanuele.reccia@gmail.com may be used to analyze more complex structures - i.e. walls, buildings, etc. - [8-16]. Alternatively, they could be treated as continuum models, usually obtained by homogenization techniques: the Cauchy continuum, the Cosserat continuum and higher order continua [17-19] are examples of this approach. At the macro-scale level there have been performed either linear analyses [20-22], or nonlinear analyses, which take into account damage phenomena [23,24] or even limit analyses [25-27].

Here a discrete model to investigate masonry behavior is proposed. It is built on the assumption that rigid blocks are connected by mortar interfaces. This hypothesis is justified since, in the case of historical masonry, mortar is much more deformable than blocks and its thickness is often negligible when compared to block dimensions. Hence blocks can be modeled as rigid bodies connected through Mohr-Coulomb type interfaces (i.e. mortar thin joints). In other words, masonry is seen as a molecular skeleton where interactions between molecules (rigid blocks) are represented by forces and moments, which depend on their relative displacements and rotations $[1,28,29]$.

In this work the feasibility of the Finite Element Method (FEM)/Discrete Element Method (DEM) [30] in dealing with the behavior of masonry structures is investigated. The DEM provides a consistent procedure to study masonry structures because of its ability to cope with separated blocks. In particular, these models can properly represent the behavior of historical masonry constructions, which could be considered as made of dry stone blocks exhibiting a periodic pattern. 
The combination of DEM and FEM allows to study both the linear and the nonlinear masonry behavior. In the proposed model blocks can be assumed to behave either as rigid or as elastic bodies while mortar joints are idealized as zero-thickness Mohr-Coulomb type interfaces. Blocks are modeled by finite elements while interfaces are modeled as discrete elements.

In the literature there are available already discrete models for masonry in the linear elastic range [20] and continuous models for limit analysis [27].

The target of this research is to compare the obtained results with more reliable models. In order to apply the FEM/DEM, which is generally used for geomechanics applications, a preliminary validation of the model with reference to masonry behavior is needed. Analyses are performed by using Y2D, an open source code developed by prof. A. Munjiza [30, 31], who has been among the pioneers of FEM/DEM coupling. A comparison with well known and meaningful examples has been carried out to validate this method. For this reason several models reproducing the studies carried out by Giuffrè about the out-of-plane behavior of masonry walls [32] have been analyzed. 2D discrete elements representing both walls sections and panels have been considered; they reproduce masonry walls with different staggered blocks: some of them do respect criteria of good construction i.e. Giuffrè's regola d'arte and some of them don't. In particular stack bond and running bond patterns have been taken into account; the latter (which satisfies regola d'arte) shows a monolithic behavior, while the stack bond pattern behaves like two separated layers.

Comparison between FEM/DEM models and the simplified Giuffrè's models allows to assess the feasibility of the proposed method to real-world examples. A subsequent research step will consist in improving the Y2D-code to make it more suitable for the analysis of masonry behavior. This can be accomplished by implementing a specific constitutive law for masonry-like materials.

\section{MASONRY MODEL}

The idea is that of investigating the out-of-plane behavior of masonry. A simple model is proposed where thickness of masonry, under in plane strain assumption, is analyzed. Masonry panel section may be considered as a periodic structure. Indeed the masonry panel section may be obtained by regular repetition - according to an internal law - of an elementary cell. In particular two texture are considered (see

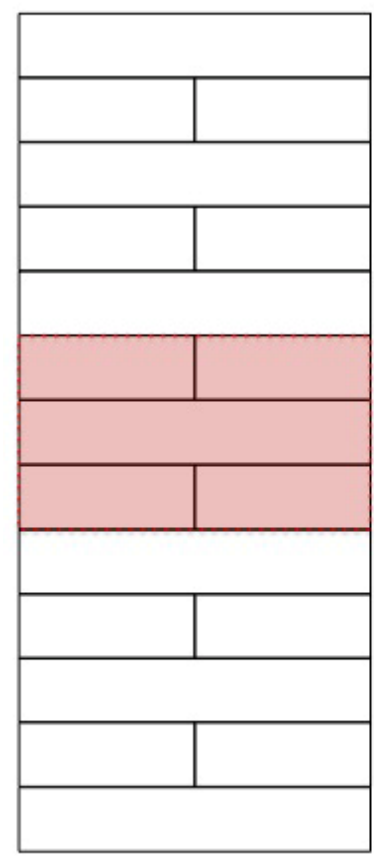

(a)

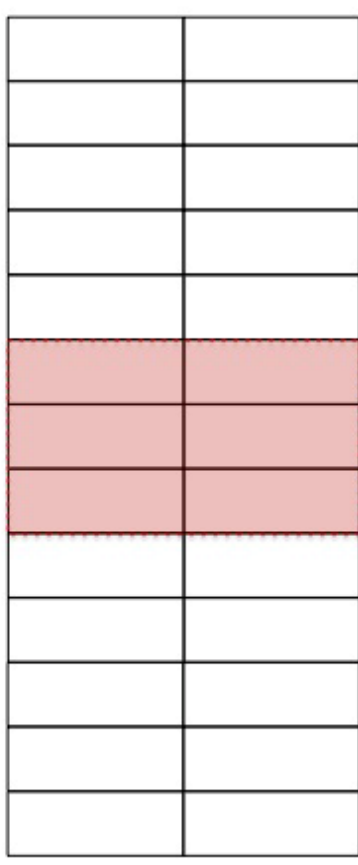

(b)
Fig. (1). Running bond (a) and stack bond (b) patterns.

Fig. 1): running bond and stack bond. The masonry out of plane behavior is very sensitive to different staggered tiers.

\subsection{Discrete Model}

Let $\mathbf{y}^{\mathrm{i}, \mathrm{j}}$ be the position of the center of the generic $B_{i, j}$ block in the Euclidean space:

$\mathbf{y}^{\mathrm{i}, \mathrm{j}}=\mathrm{i} \frac{\mathrm{b}}{4} \mathbf{e}_{1}+\mathrm{ja \mathbf {e } _ { 2 }}$.

As it is shown in Fig. (2), where representative volume elements of both textures are presented, $j$ can actually take arbitrary values while $i$ is such that the sum $i+j$ is always an even number.

Due to the regularity of the masonry structure, the $B_{i, j}$ block interacts with the $B_{i+k_{1}, j+k_{2}}$ block by means of $\Sigma_{k_{1}, k_{2}}^{i, j}$ joints Fig. (3).
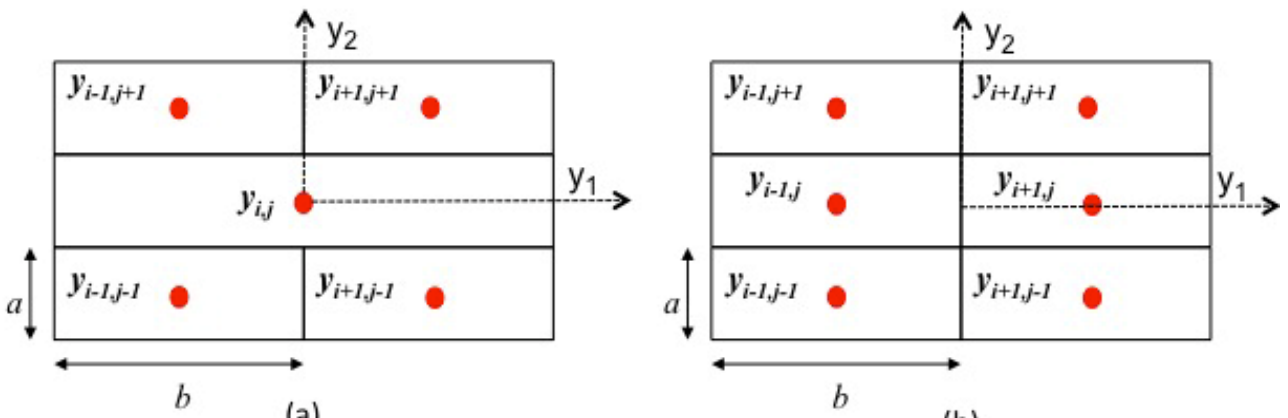

(b)

Fig. (2). Representative volume elements of the running bond (a) and of the stack bond pattern (b) 


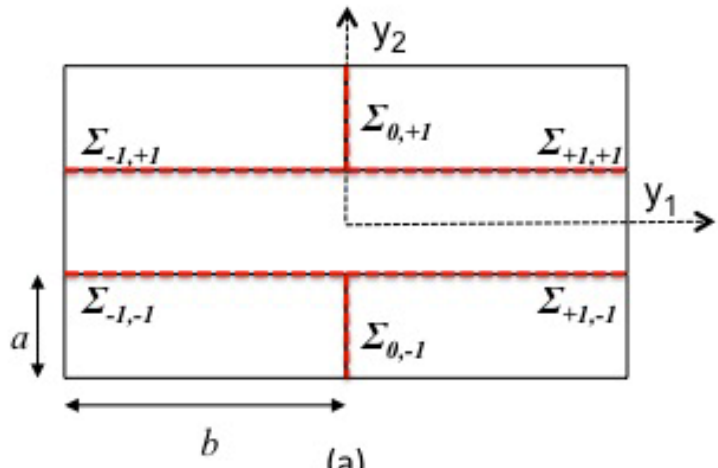

(a)

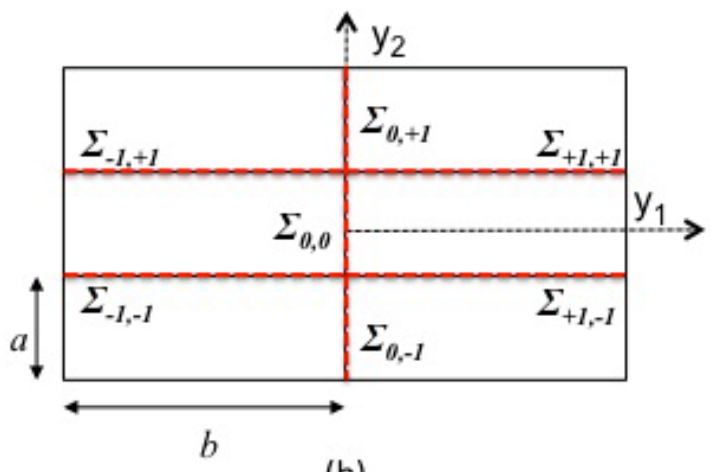

(b)

Fig. (3). Interfaces between blocks in the running bond (a) and in the stack bond pattern (b)
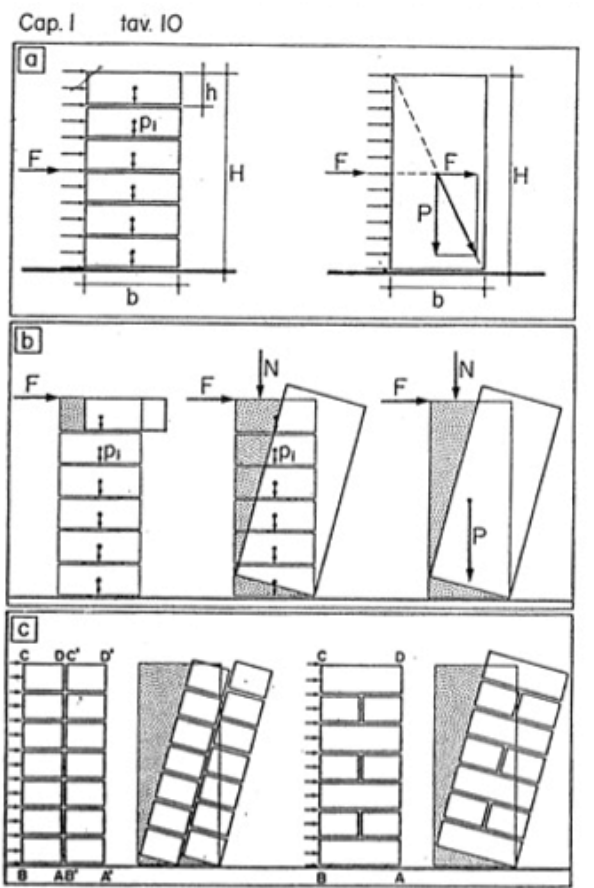

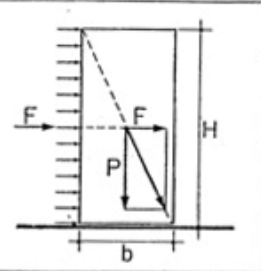

N

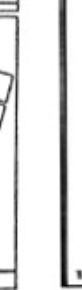

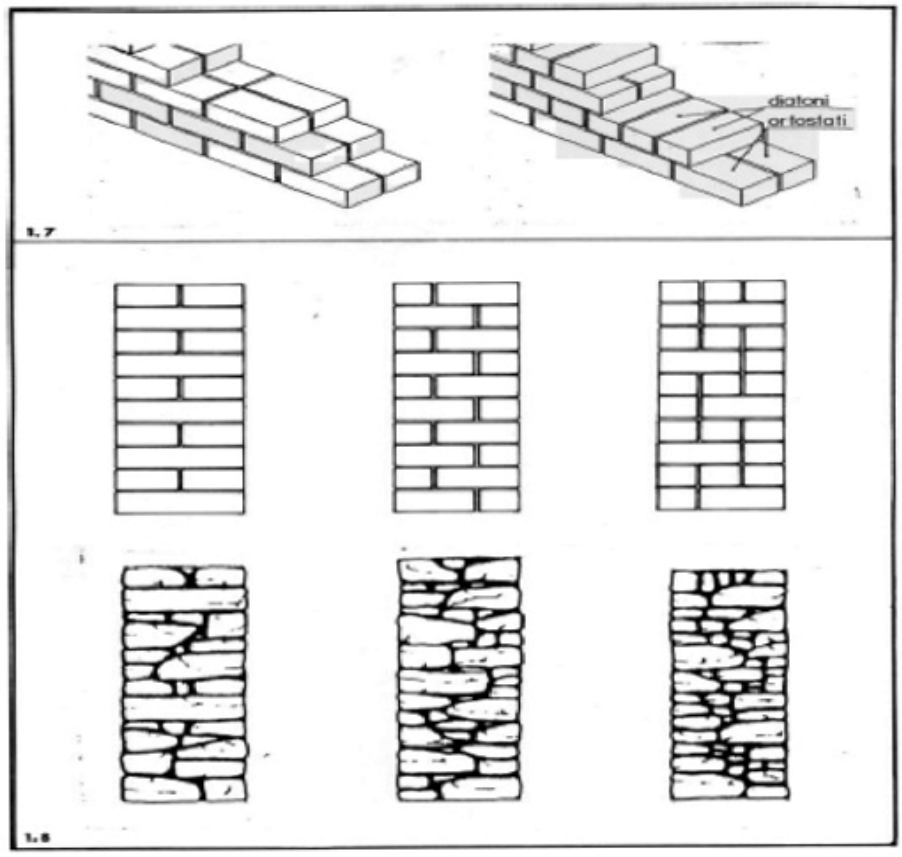

Fig. (4). Collapse mechanisms of walls cross sections for different textures, taken from Giuffrè[32].

If the mortar joint is modeled as an interface - such a problem has been studied by Klarbring [33] using perturbative techniques in the elastic case - the deformation between two blocks may be written as a function of the displacement jump.

The displacement of each block is a rigid body motion:

$\mathbf{u}=\mathbf{u}^{\mathrm{i}, \mathrm{j}}+\boldsymbol{\Omega}^{\mathrm{i}, \mathrm{j}} \times\left(\mathbf{y}-\mathbf{y}^{\mathrm{i}, \mathrm{j}}\right), \quad \forall \mathbf{y} \in \mathrm{B}_{\mathrm{i}, \mathrm{j}}$

where $\mathbf{u}^{\mathrm{i}, \mathrm{j}}$ is a translation vector and $\boldsymbol{\Omega}^{\mathrm{i}, \mathrm{j}}$ is an infinitesimal rotation vector of $B_{i, j}$.

In the 2D case, which is the only one which is considered here, the components of the displacement vector are written in a compact form as: $\mathbf{u}=\left(\mathrm{u}_{1}, \mathrm{u}_{2}, \Omega_{3}\right)^{\mathrm{T}}$.

Since blocks are rigid, we assume as a measure of deformation the jump $\left\lfloor\mathbf{u} \int_{\mathrm{k}_{1}, \mathrm{k}_{2}}^{\mathrm{i}, \mathrm{j}}\right.$ at the interface $\Sigma_{\mathrm{k}_{1}, \mathrm{k}_{2}}^{\mathrm{i} \mathrm{j}}$ between blocks $B_{i, j}$ and $B_{i+k_{1}, j+k_{2}}$. This jump is obtained from the following expression:

$$
\begin{aligned}
& \lfloor\mathbf{u}\rfloor_{-k_{1}, k_{2}}^{i, j}=\mathbf{u}^{i+k_{1}, j+k_{2}}-\mathbf{u}^{i, j}+\boldsymbol{\Omega}^{i+k_{1}, j+k_{2}} \times\left(\mathbf{y}-\mathbf{y}^{i+k_{1}, j+k_{2}}\right)+
\end{aligned}
$$

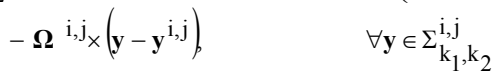

It has been shown in Cecchi and Sab [20] that $\mathbf{u}^{i}$ and $\boldsymbol{\Omega}^{\mathbf{i}}$ can be expressed in terms of the infinitesimal strain $\mathbf{E}=\frac{1}{2}\left(u_{\alpha, \beta}+u_{\beta, \alpha}\right)$, and of 3 yet undetermined rigid body displacement parameters, ( 2 translations and 1 rotation); the jump of the displacement field at the interface depends only on $\mathbf{E}$, and on the undetermined rotation, $\Omega_{3}$.

When the response is elastic, the constitutive tensor $\mathbf{K}$ between the $\mathbf{t}$ tractions at the $\Sigma_{k_{1}, k_{2}}$ interface and the $\lfloor\mathbf{u}\rfloor$ jump of the displacement field at the $\Sigma_{\mathrm{k}_{1}, \mathrm{k}_{2}}$ interface is given, component-wise by: 
$\mathrm{K}_{\mathrm{ij}}=\frac{1}{\mathrm{e}} \mathrm{a}_{\mathrm{iklj}}^{\mathrm{M}} \mathrm{n}_{\mathrm{k}} \mathrm{n}_{1}$.

Here e is the thickness of the real joint, $\mathbf{a}^{\mathrm{M}}$ is the mortar constitutive functions and $\mathbf{n}$ is the normal to the interface. In the isotropic case, the above expression becomes:

$\mathbf{K}=\frac{1}{\mathrm{e}}\left[\frac{\mathrm{E}^{\mathrm{M}}}{2\left(1+v^{\mathrm{M}}\right)}\left(\mathbf{I}+\frac{1}{\left(1-2 v^{\mathrm{M}}\right)}(\mathbf{n} \otimes \mathbf{n})\right)\right]$

where $\mathrm{E}^{\mathrm{M}}$ is the Young modulus of mortar, $v^{\mathrm{M}}$ its Poisson ratio and $\mathbf{I}$ is the identity tensor. Note that tensor $\mathbf{K}$ has, in this case, a diagonal form.

At collapse, the $\mathbf{t}$ tractions at the $\Sigma_{k_{1}, k_{2}}$ interface obey the Mohr-Coulomb yield criterion. The cohesionless MohrCoulomb criterion at a point of $\Sigma_{k_{1}, k_{2}}$ interface is:

$\mathrm{F}(\mathbf{t}, \mathbf{n}, \phi)=\mathrm{t}_{\mathrm{n}} \tan \phi-\mathrm{c}+\left|\mathbf{t}^{\perp}\right| \leq 0$

where $\mathbf{n}$ is the normal to $\Sigma_{k_{1}, k_{2}}$ interface, $t_{n}=\mathbf{t} \cdot \mathbf{n}$ is the normal component of $\mathbf{t}$, and $\mathbf{t}^{\perp}$ is the orthogonal component of $\mathbf{t}$. The Mohr-Coulomb support function (see [34] is:

$\left\langle\pi\left(\operatorname{grad}^{\mathrm{s}} \mathbf{u}\right)\right\rangle= \begin{cases}\frac{1}{\mathrm{ab}} \int_{\Sigma_{\mathrm{k}_{1}, \mathrm{k}_{2}}}\left(\frac{\mathrm{c}}{\tan \phi}\right)\lfloor\mathbf{u}\rfloor \cdot \mathbf{n} & \text { if }\lfloor\mathbf{u}\rfloor \cdot \mathbf{n} \geq\lfloor\mathbf{u}\rfloor^{\perp} \mid \tan \phi \\ +\infty & \text { otherwise }\end{cases}$

where, $\lfloor\mathbf{u}\rfloor$ is the velocity jump across the joint interface $\Sigma_{\mathrm{k}_{1}, \mathrm{k}_{2}}, \quad \mathbf{n}$ is the normal to the $\Sigma_{\mathrm{k}_{1}, \mathrm{k}_{2}}$ interface, $\lfloor\mathbf{u}\rfloor^{\perp}=\lfloor\mathbf{u}\rfloor-(\lfloor\mathbf{u}\rfloor \cdot \mathbf{n}) \mathbf{n}$ is the orthogonal component of $\lfloor\mathbf{u}\rfloor, 0 \leq \mathrm{c}$ is the cohesion parameter and $0<\phi<\frac{\pi}{2}$ is the friction angle; $\mathrm{a}$ is the height and $\mathrm{b}$ is the width of the block.

It must be noticed that $\lfloor\mathbf{u}\rfloor$ is a piecewise-linear field on $\Sigma_{k_{1}, k_{2}}$ which can be expressed as a function of the strain tensor $\mathbf{E}$, and of the infinitesimal rotation, $\Omega_{3}$.

Two masonry pattern are studied: the running bond and the stack bond cases. In particular it should be observed that

- if $\mathrm{k}_{1}, \mathrm{k}_{2}= \pm 1$, then $\Sigma_{\mathrm{k}_{1}, \mathrm{k}_{2}}$ is always an horizontal interface;

- if $\mathrm{k}_{1}=0$ and $\mathrm{k}_{2}= \pm 1$, then $\Sigma_{\mathrm{k}_{1}, \mathrm{k}_{2}}$ is a vertical interface in the case of the running bond;

- if $\mathrm{k}_{1}=0$ and $\mathrm{k}_{2}=0$, then $\Sigma_{\mathrm{k}_{1}, \mathrm{k}_{2}}$ is a vertical interface in the case of the stack bond.

The interfaces of the $B_{i, j}$ block are defined as follows.

- both for the running bond and the stack bond cases:
$\Sigma_{-1,-1}^{\mathrm{k}_{1}, \mathrm{k}_{2}}=\left(\begin{array}{c}-\frac{\mathrm{b}}{2} \leq \mathrm{y}_{1} \leq 0 \\ \mathrm{y}_{2}=-\mathrm{a} 2\end{array}\right) ; \quad \Sigma_{+1,-1}^{\mathrm{k}_{1}, \mathrm{k}_{2}}=\left(\begin{array}{c}0 \leq \mathrm{y}_{1} \leq+\frac{\mathrm{b}}{2} \\ \mathrm{y}_{2}=-\mathrm{a} 2\end{array}\right) ;$

$\Sigma_{+1,+1}^{\mathrm{k}_{1}, \mathrm{k}_{2}}=\left(\begin{array}{c}0 \leq \mathrm{y}_{1} \leq+\frac{\mathrm{b}}{2} \\ \mathrm{y}_{2}=\frac{\mathrm{a}}{2}\end{array}\right) ; \quad \Sigma_{-1,+1}^{\mathrm{k}_{1}, \mathrm{k}_{2}}=\left(\begin{array}{c}-\frac{\mathrm{b}}{2} \leq \mathrm{y}_{1} \leq 0 \\ \mathrm{y}_{2}=\frac{\mathrm{a}}{2}\end{array}\right) ;$

- only for the stack bond there is an additional vertical interface:

$\Sigma_{0,0}^{\mathrm{k}_{1}, \mathrm{k}_{2}}=\left(\begin{array}{c}\mathrm{y}_{1}=0 \\ -\frac{\mathrm{a}}{2} \leq \mathrm{y}_{2} \leq \frac{\mathrm{a}}{2}\end{array}\right)$.

\section{MASONRY ANALYSIS: SOME MEANINGFUL CASES}

The idea is that of reproducing some experiments performed by Giuffrè to evaluate the effect of texture in the out-of-plane masonry behavior Fig. (4).

The first step consists of analyzing monolithic blocks. A monolithic block subject to a lateral force acting at its upper edge has two possibilities of collapse: sliding or overturning, depending on its thickness-to-height ratio.

The second step involves the analysis of masonry made of superimposed blocks. When sliding is concerned, a lateral force acting on the upper block produces sliding of that block only. But when the thickness of the wall is larger than a single block and overturning is considered the efficiency of diatoni (i.e. stiffening blocks with their longest edge lying parallel to horizontal forces) is accounted for.

Hence four representative cases are reported here: monolithic wall (Fig. 5a), two layers monolithic wall without connecting diatoni (Fig. 5b), running bond wall (Fig. 5c) and stack bond wall (Fig. 5d). In the running bond pattern the presence of stiffening diatoni might be noticed. For each of the considered cases the two failure mechanism of sliding or overturning may occur.

\section{NUMERICAL TESTS}

\subsection{The FEM-DEM Model}

The most widely used method in computational solid mechanics is the Finite Element Method. In recent decades a set of computational methods has been developed to deal with particulates, jointed rock, granular flows and problems where the so called emergent properties of a system are a result of interaction between a large number of individual solid particles. The most widely used method for a large class of these problems is the Discrete Element Method. In the early 1990s the two methods have been combined and the resulting method is now known as the combined FEMDEM [30]. It is in essence a discrete element method with individual elements meshed into finite elements. Finite elements allow to model elastic deformation (if any), while discrete element algorithms allow to deal with interaction, fracture and fragmentation processes. 


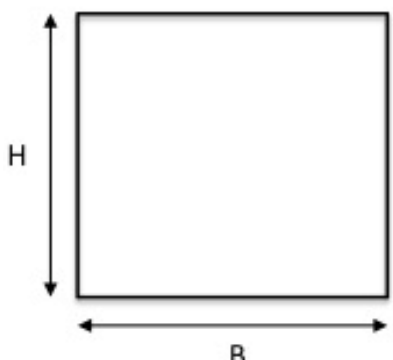

(a)

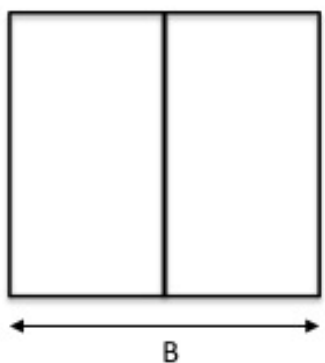

(b)

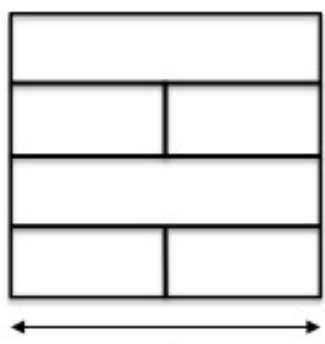

B

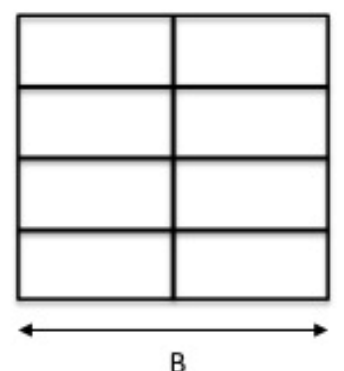

(d)

Fig. (5). Monolithic wall (a); Two layers wall without diatoni (b); Running bond wall (c); Stack bond wall (d).

Table 1. Mechanical Properties of Joints

\begin{tabular}{|c|c|c|c|c|}
\hline Joint & Friction & Cohesion [MPa] & Tensile Strength [MPa] & Fracture Energy [N/m] \\
\hline \hline Inside bricks & 0.5 & 1000. & 100. & 1000. \\
\hline Horizontal mortar & 0.5 & $1 \cdot 10^{-6}$ & $1 \cdot 10^{-6}$ & 0.1 \\
\hline Vertical mortar & 0.1 & $1 \cdot 10^{-6}$ & $1 \cdot 10^{-6}$ & 0.1 \\
\hline
\end{tabular}

\subsection{Analyses Details}

Analyses have been carried out by using Y2D, an open source FEM/DEM code [31]. Models represent a vertical section of different masonry walls exhibiting various $\xi=\mathrm{B} / \mathrm{H}$ ratios, $\mathrm{B}$ being the wall thickness and $\mathrm{H}$ the wall height, and different textures. Meshes are made of 3-nodes 2D elements with a characteristic lenght of $0.06 \mathrm{~m}$. Each blocks is discretized by 8 elements, in order to have different bond patterns, and two layers of bricks are grouped into one. The number of the elements in the models varies from 64 to 256. The number of timestep of the analysis is 10000 . The wall thickness B has been always kept equal to $0.48 \mathrm{~m}$, while the $\xi$ ratio varies in the range $0.4 \div 4$, depending on the number of horizontal joints.

\subsection{Material Properties}

Mechanical characteristics of materials are the following: Young's modulus of block $\mathrm{E}^{\mathrm{b}}=1000 \mathrm{MPa}$, Young's modulus of mortar $\mathrm{E}^{\mathrm{M}}=1 \times 10^{-6} \mathrm{MPa}$, Poisson's ratio of block and mortar $v^{\mathrm{B}}=v^{\mathrm{M}}=0$, hence hypothesis of transversally incompressible material is assumed. It may be noticed that the ratio between Young's modulus of block, $E^{b}$ and mortar, $\mathrm{E}^{\mathrm{M}}$ is $10^{9}$, hence block may be considered as infinitely rigid with reference to the joints. Density of block is $\rho^{B}=1800 \mathrm{~kg} / \mathrm{m}^{3}$.

\subsection{Joints Characterization}

Three different joints have been used. The strongest joint has been-adopted inside bricks. This is justified because bricks are modeled as rigid blocks with infinite compressive strength. For mortar joints, Eq. (6) is used with $c=0$; hence a frictional only Mohr-Coulomb joint has been considered. However different joint properties have been used for horizontal and for vertical mortar joints, the former being stronger than the latter.

Indeed, horizontal joints strength is influenced by friction depending on the weight of that part of the wall lying above it, while vertical joints strength depends only on the horizontal force. In this way, the circumstance that mortar can be very weak or even absent, as in the case of some historical masonry, is implicitly taken into account by considering the joint as an interface instead than taking into account its elastic properties. Synthetically, results presented here correspond to the case of dry stone masonry. Mechanical properties of joints are summarized in Table $\mathbf{1 .}$

\subsection{Mechanism Depending on $\xi$ Ratio}

A $F_{1}$ horizontal force and a $F_{2}$ vertical force have been applied to the models. The model height and the intensity of horizontal force vary in order to investigate the out-of-plane behavior of masonry walls, reproducing the experiments carried out by Giuffrè [32]. The two forces are however related because $F_{1}$ depends on $F_{2}$, which represents the weight of the wall and therefore depends on its height. The horizontal force can produce, as already mentioned, two different mechanisms: sliding or overturning.

By elementary statics, the horizontal force that provides sliding is:

$\mathrm{F}_{1}^{\mathrm{S}}=\mathrm{F}_{2} \tan \phi$,

while the horizontal force that produces an overturning mechanisms is:

$\mathrm{F}_{1}^{\mathrm{o}}=\mathrm{F}_{2} \xi / 2$,

where $\xi=\mathrm{B} / \mathrm{H}$ is the dimensionless thickness to height ratio. For masonry, the value of friction parameter $\tan \phi$ varies approximately between 0.4 to 0.6 ; for this reason an average value of $\tan \phi=0.5$ has been adopted here. 
When $\mathrm{F}_{1}^{\mathrm{S}}<\mathrm{F}_{1}^{\mathrm{O}}$ sliding is the collapse mechanism; otherwise, when $\mathrm{F}_{1}^{\mathrm{s}}>\mathrm{F}_{1}^{\mathrm{o}}$, collapse is due to overturning. By comparing $\mathrm{F}_{1}^{\mathrm{S}}$ and $\mathrm{F}_{1}^{\mathrm{o}}$ it is possible to observe that there is a limit value of the ratio $\xi$ which identifies the transition from sliding to overturning:

$$
\xi_{\lim }=2 \tan \varphi t
$$

Models with different values of $\xi$ have been tested and each one has been subjected to the minimum horizontal force between $\mathrm{F}_{1}^{\mathrm{s}}$ and $\mathrm{F}_{1}^{\mathrm{o}}$. In all cases, see Fig. (6), the expected collapse mechanism was recovered. The numerical tests for $\tan \phi=0.5$ show that the limit value $\mathrm{F}_{1}^{\mathrm{S}}=\mathrm{F}_{1}^{\mathrm{O}}$ corresponds to $\xi=1$

\subsection{Sliding}

The sliding mechanism fully agrees with Eq. (8). It is clear that, since vertical loads coincide with the self-weight of blocks, global sliding occurs in the cases of monolithic or two layers walls. Instead in the cases of stack and running bond walls sliding phenomena start from the top layer and subsequently extend to the lower ones, as shown in Fig. (7). Moreover, the horizontal displacements of the stack bond

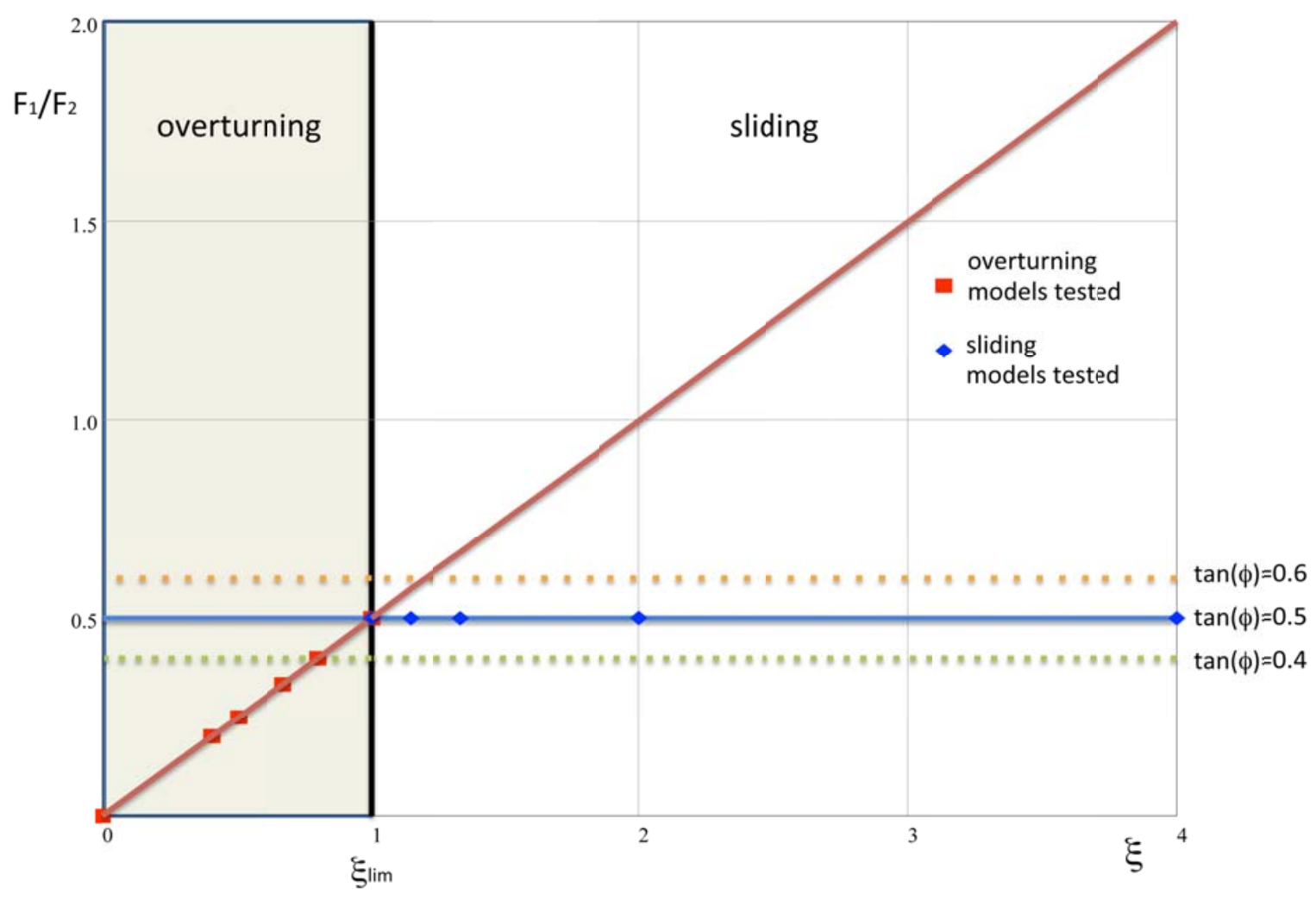

Fig. (6). Dimensionless collapse mechanisms as a function of the horizontal to vertical force ratio. Overturning and sliding regions are outlined.

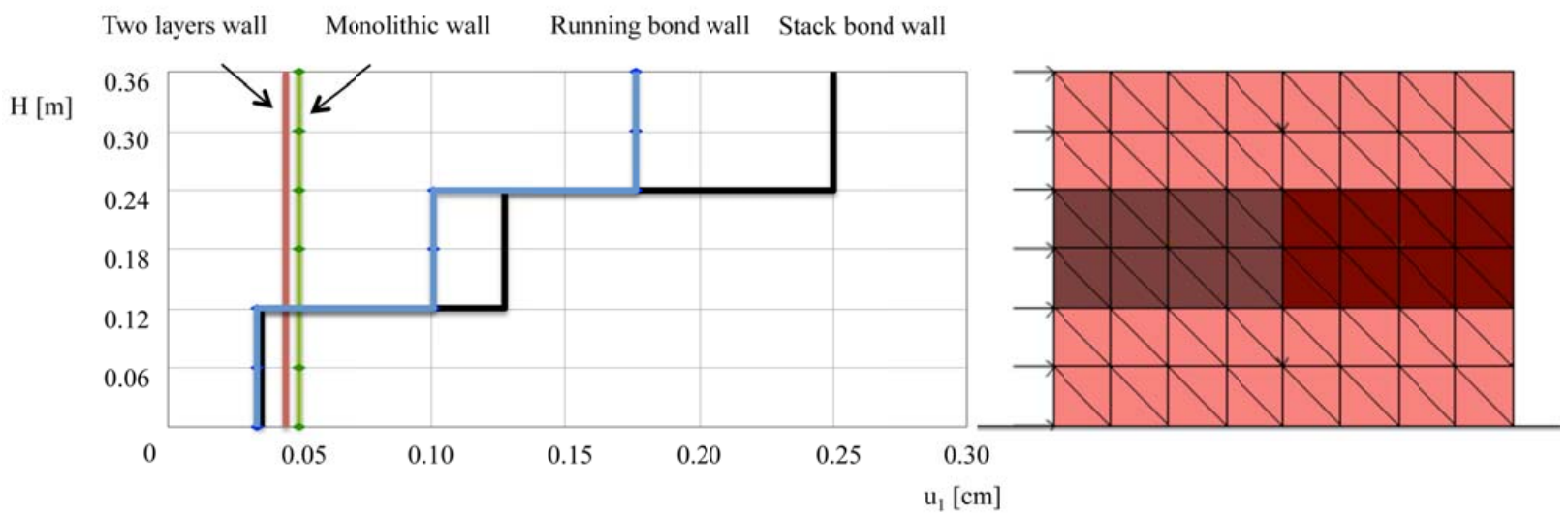

Fig. (7). Sliding displacements for the analyzed wall patterns. 
pattern are larger, if compared to the running bond: this can be explained because the vertical load, which is responsible of friction, depends in the former case only on a single block (and not on two) and is, therefore, just one half of that occurring in the latter case.

\subsection{Overturning}

For overturning the stagger of running bond pattern provides a monolithic behavior; for the stack bond, instead, the lack of such a device does not allow the occurrence of monolithic behavior and the two vertical curtains behave as being independent.

As a consequence, there is a similarity of response between the monolithic and the running bond wall, on one side (see Fig. 8); and between the two layers wall and the stack bond wall on the other one (see Fig. 9).

Other, more complex patterns, like those presented in Giuffrè [32] would exhibit an intermediate behavior between those shown here.

\section{CONCLUSIONS}

All tested cases appear to be in good agreement with Giuffrè's results. As a conclusion, this study shows that applications of FEM/DEM to out-of-plane analysis of masonry walls are feasible and provide reliable results. The next step of this work will involve analyzing with FEM/DEM other types of patterns especially those with internal incoherent filling. The following conclusions can be drawn:

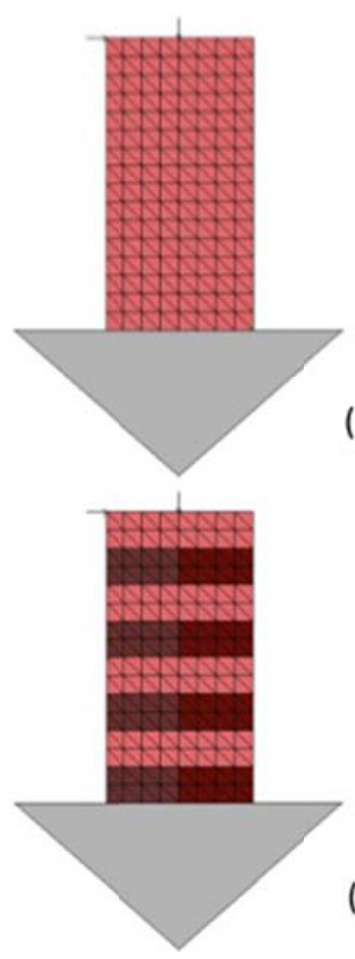

(a)

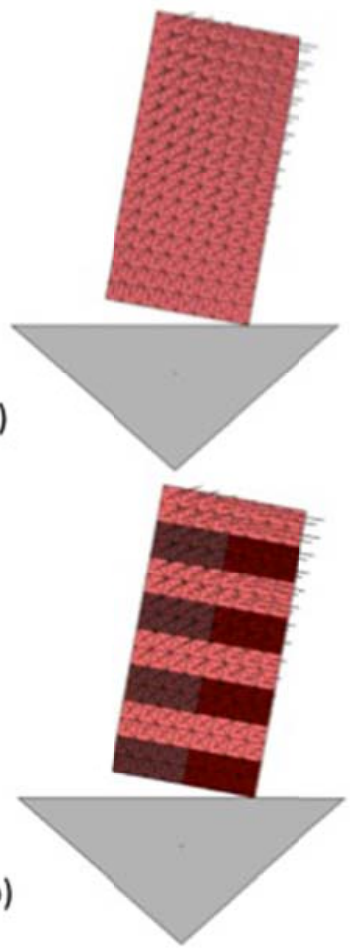

Fig. (8). Overturning mechanism for the monolithic (a) and the running bond $(\boldsymbol{b})$ walls.
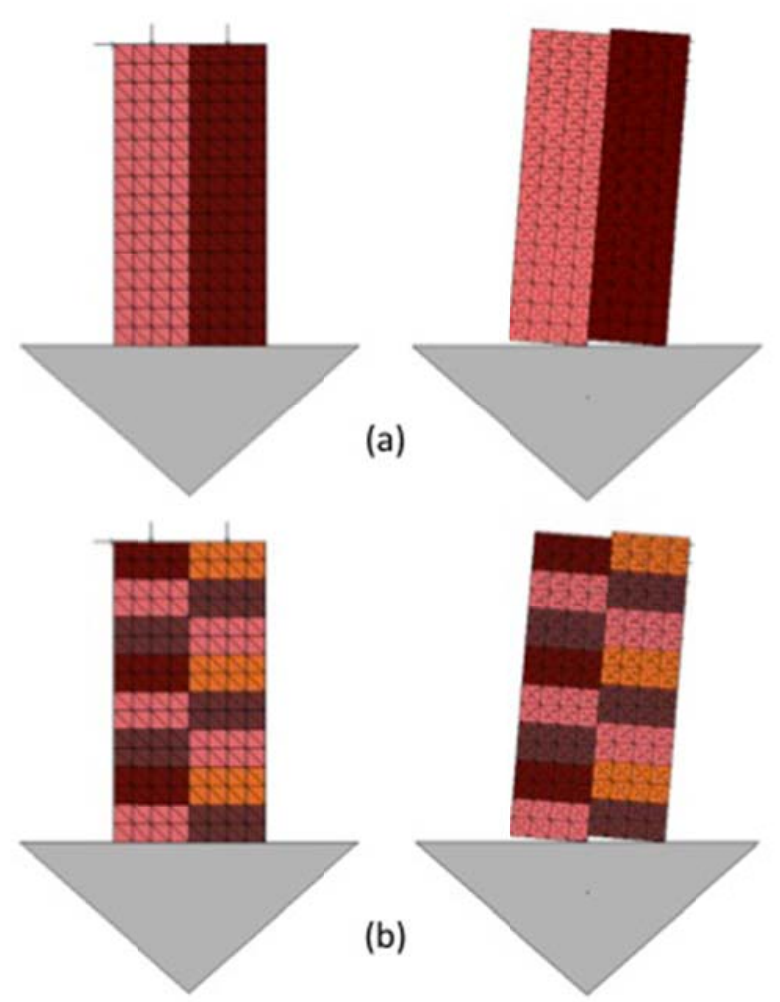

(b)

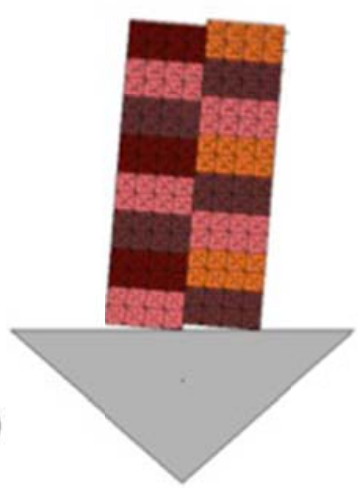

Fig. (9). Overturning mechanism for the two layers (a) and the stack bond $(\boldsymbol{b})$ walls.

1) A masonry correctly built must be characterized by horizontal lines and regular transversal connections.

2) The lack of transversal connections makes masonry unfit to resist to rocking motions.

3) The strength of wall against out-of-plane forces strongly depends on the arrangement of blocks.

4) A regular arrangement of blocks, as in the so called regola d'arte, produces a behavior similar to that of a monolithic body. A less effective texture provides a decrease of mechanical performances.

5) The Mohr-Coulomb model is appropriate to represents load transmission between blocks. Blocks interlocking produces, through friction, a pseudo-tensile resistance, which is a function of the compressive stresses acting on the sliding surface.

6) DEM models are particularly appropriate to describe the behavior of brickworks with different textures and especially those idealized as dry block masonries.

\section{CONFLICT OF INTEREST}

The authors confirm that this article content has no conflicts of interest.

\section{ACKNOWLEDGEMENTS}

The authors wish to thank the Geomechanics Group at Department Civil Engineering University of Toronto and, in particular, Giovanni Grasselli and Andrea Lisjak. The 
financial support of University of Cagliari is gratefully acknowledged.

\section{REFERENCES}

[1] P.B. Lourenço and J.G. Rots, "Discrete models for jointed block masonry walls", in Sixth North American Masonry Conference, Philadelphia, 1993, pp. 939-959.

[2] G. Alpa and I. Monetto, "Microstructural Model for Dry Block Masonry Walls with In-Plane Loading", J. Mech. Phy. Solids, vol. 47, pp. 1159-1175, 1994.

[3] H.R. Lofti and P. B. Shing, "Interface model applied to fracture of masonry structures", ASCE J. Struct. Eng., vol. 120, pp. 63-80, 1994.

[4] P. Trovalusci and R. Masiani, "Cosserat and Cauchy materials as continuum models of brick masonry", Meccanica, vol. 31, pp. 421432, 1996.

[5] P. de Buhan and G. de Felice, "A homogenization approach to the ultimate strength of brick masonry", J. Mech. Phys. Solids, vol. 45, pp. 1085-1104, 1997.

[6] P.B. Lourenço, "Computational Strategies for Masonry Structures", PhD thesis, Delft University, Delft, The Netherlands, 1996.

[7] A. Cecchi and K. Sab, "A comparison between a 3D discrete model and two homogenised plate models for periodic elastic brickwork", Int. J. Solids Struct., vol. 41, pp. 2259-2276, 2004.

[8] V. Turnšek and F. Čačovič, "Some experimental results on the strength of brick masonry walls", in Second International Brick Masonry Conference, Stoke-on-Trent, 1971, pp. 149-156.

[9] M. Tomaševič and V. Turnšek, "Lateral load distribution as a basis for the seismic resistance analysis of masonry buildings", In International Research Conference on Earthquake Engineering, Skopje, 1980, pp. 455-488.

[10] V. Turnšek and P. Sheppard, "The shear and flexural resistance of masonry walls", In International Research Conference on Earthquake Engineering, Skopje, 1980, pp. 517-573.

[11] F. Braga and M. Dolce, "A method for the analysis of antiseismic masonry multi-storey buildings", In Sixth International Brick Masonry Conference, Roma, 1982, pp. 1088-1098.

[12] P. D'Asdia and A.L. Viskovi, "Analisi sismica degli edifici in muratura”, Ingegneria Sismica, vol. 1, pp. 32-42, 1994.

[13] L. Gambarotta and S. Lagomarsino, "Damage models for the seismic response of brick masonry shear walls. Part I: the mortar joint model and its applications", Earthquake Eng. Struct. Dyn., vol. 26, pp. 423-439, 1997.

[14] L. Gambarotta and S. Lagomarsino, "Damage models for the seismic response of brick masonry shear walls. Part II: the continuum model and its applications", Earthquake Eng. Struct. Dyn., vol. 26, pp. 441-462, 1997.

[15] G. Magenes and G.M. Calvi, "In-plane seismic response of brick masonry walls", Earthquake Eng. Struct. Dyn., vol. 26, pp. 10911112, 1997.

[16] N. Augenti, Il Calcolo Sismico Degli Edifici in Muratura, UTET: Torino, 2000.
[17] A. Anthoine, "Derivation of in plane elastic characteristic of masonry through homogenization theory", Int. J. Solids Struct., vol. 32, pp. 137-163, 1995.

[18] R. Masiani, N.L. Rizzi and P. Trovalusci, "Masonry walls as structured continua", Meccanica, vol. 30, pp. 673-683, 1995.

[19] T. Massart, R.H.J. Peerlings and M.G.D. Geers, "An enhanced multi-scale approach for masonry wall computations with localization of damage", Int. J. Num. Methods Eng., vol. 69, pp. 1022-1059, 2007.

[20] A. Cecchi and K. Sab, "Out of plane model for heterogeneous periodic materials: the case of masonry", Eur. J. Mech. A Solids, vol. 21, pp. 249-268, 2002.

[21] A. Cecchi and K. Sab, "A comparison between a 3D discrete model and two homogenised plate models for periodic elastic brickwork", Int. J. Solids Struct., vol. 41, pp. 2259-2276, 2004.

[22] G. Salerno and G. de Felice, "Continuum modeling of periodic brickwork”, Int. J. Solids Struct., vol. 46, pp. 1251-1267, 2009.

[23] R. Luciano and E. Sacco, "Homogenization Technique and Damage Model for Old Masonry Material", Int. J. Solids Struct., vol. 34, pp. 3191-3208, 1997.

[24] B. Shieh-Beygi and S. Pietruszczak, "Numerical analysis of structural masonry: mesoscale approach", Comput. Struct., vol. 86, pp. 1958-1973, 2008.

[25] G. Milani, P.B. Lourenço and A. Tralli, "Homogenized limit analysis of masonry walls: structural examples", Comput. Struct., vol. 84, pp. 181-195, 2006.

[26] K. Sab, "Yield design of thin periodic plates by a homogenization technique and an application to masonry walls", Comptes Rendus Mécanique, vol. 331, pp. 641-646, 2003.

[27] A. Cecchi and G. Milani, "A kinematic limit analysis model for thick English bond masonry walls", Int. J. Solids Struct., vol. 45, pp. 1302-1311, 2008.

[28] H.R. Lofti and P. Benson Shing, "Interface model applied to fracture of masonry structures", ASCE J. Struct. Eng., vol. 120, pp. 63-80, 1994.

[29] K.Z. Markov, "Elementary micromechanics of heterogeneous solids", In: Heterogeneous Media: Micromechanics Modeling Methods and simulations, K.Z. Markov and L. Preziosi Eds, Birkhauser: Boston: 1999, pp. 1-162.

[30] A. Munjiza, The Finite/Discrete Element Method, John Wiley and Sons: Chichester 2004.

[31] O. K. Mahabadi, G. Grasselli and A. Munjiza, "Y-GUI: A graphical user interface and pre-processor for the combined finitediscrete element code, Y2D, incorporating material inhomogeneity", Comput. Geosci., vol. 36, pp. 241-252, 2010.

[32] A. Giuffrè, Letture sulla meccanica delle murature storiche, Edizioni Kappa: Roma 1991 (In Italian).

[33] A. Klarbring, "Derivation of model of adhesively bounded joints by the asymptotic expansion method", Int. J. Eng. Sci., vol. 29, pp. 493-512, 1991.

[34] J. Salençon, "An introduction to the yield desig theory and its application in soil mechanics", Eur. J. Mech. A Solids, vol. 9, pp. 477-550, 1990. 